\title{
Card-Image Public Access Catalogues (CIPACs): Issues Concerned with their Planning and Implementation
}

\author{
O. C. OBERHAUSER \\ Vienna, Austria
}

This article identifies and discusses the issues and problems that need to be considered in the process of planning and implementing card-image public access catalogues (CIPACs). CIPACs are online library catalogues based on databases of digitised catalogue cards with more or less sophisticated mechanisms for browsing or searching. Solutions of this kind have been implemented by a number of libraries in various countries since the mid-1990s, mainly as inexpensive alternatives to full retrospective conversion of their old catalogues. Based upon a questionnaire and relevant literature, the article looks at the following aspects: cost, conversion speed, universal access, saving of space, preservational aspects, software selection, preparing the card catalogue for conversion, scanning and quality control, image standards, optical character recognition, manual and intellectual input, technological aspects, administrative tools, organisational aspects, peculiarities of old catalogues, presentation of CIPACs to the users, and life expectancy of card-image catalogues.

\section{Background}

Since the introduction of automated library systems and of online public access catalogues in particular, one of the greatest challenges for library managers has been the transfer of older records into the OPACs. Some libraries have already achieved this goal, but many others are still far away from closing their old card, sheaf or book catalogues. Recataloguing is expensive and, therefore, normally not feasible on a large scale (Dugall 2001). However, the conversion of existing records into machine-readable records (retroconversion) is not cheap either. Studies of large conversion projects have shown that the average cost per record is between 2.42 and 4.23 Euros (Beyersdorff 1993; Bryant 1997; Leeves, Butler \& Mealia 1999), which means that for larger projects or national programmes enormous sums of money are required.

The digitisation (scanning) of catalogue cards has become common practice in retroconversion not only as a prerequisite for approaches that involve optical character recognition (OCR), but also when a digital duplicate of the catalogue is needed to support conversion work on a computer screen. As scanning can be done quickly and at reasonable cost, the idea emerged to apply suitable browsing software to the collection of card-images. This would make it possible to offer an auxiliary or provisional online catalogue - maybe not a "real" OPAC but a very reasonably priced alternative (see the section on cost below). The first known example of such a card-image OPAC was established at the Princeton University Library in 1994 (Henthorne 1995). From the mid-1990s on, similar catalogues started to appear in Europe, with some variation of the browsing component [1] but always displaying the digital image of a catalogue card as the full view of a retrieved record (Figure 1). Some of these catalogues were originally offered on in-house networks, but soon the WWW became the commonly used platform. By mid2001 (when the questionnaire mentioned in the following sections was sent out), 38 catalogues had been identified and listed on a dedicated Web page [2]; by the end of 2002 this number has

Otto Oberhauser works for the Austrian Library Network, Vienna, but writes in his capacity as a former Masters student, School of Information Studies, University of Central England, Birmingham, UK. E-mail: oberh@web.de 
Figure 1: A typical record display in a card-image catalogue

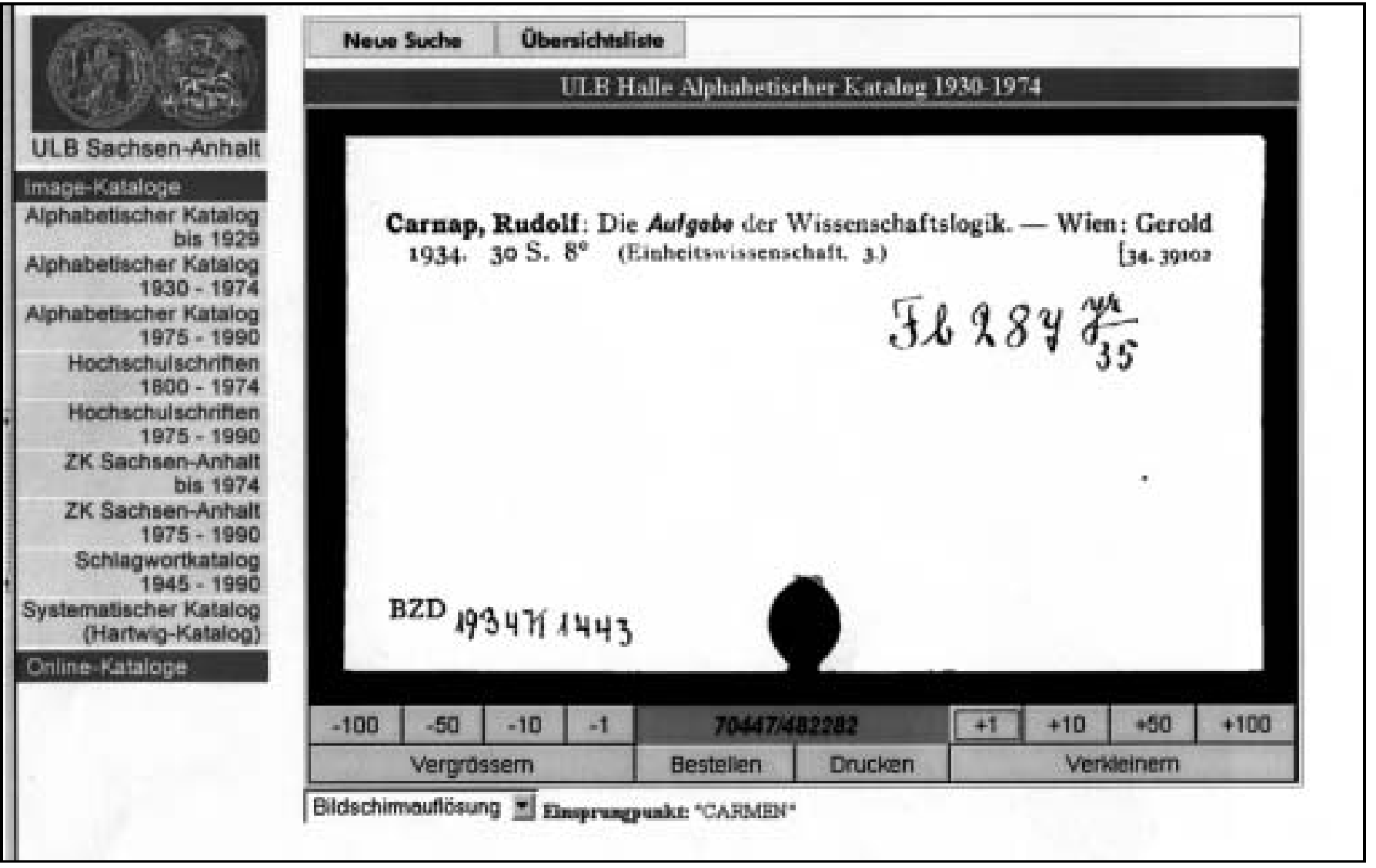

gone up to 60 catalogues in eleven countries (Figure 2).

Other advantages of such computerised cardcatalogues over their predecessors are retrieval speed, saving of users' time (by searching from home), independence from opening hours, multidimensional search options (if headings/entries are offered as searchable text), printing out and/ or downloading of records, online book ordering (appropriate components can be attached to the display of card-images), and the saving of library space (making it possible to remove the card cabinets). However, from a critical point-of-view one could also argue that in most cases no options for retrieval are offered that exceed those of traditional card catalogues, that the users might be frustrated by such solutions, and that modern information technology is used (or abused) for the resurrection and perpetuation of an outdated medium (catalogue cards).

So far, no standard terminology has been established for catalogues of this kind. Often they are referred to as "electronic", "scanned" or "digitised" card catalogues, or simply as "image catalogues" (mainly in the German-speaking countries). Here, not only the terms card-image catalogues and card-image OPACs will be used, but also - as an analogy to the widely used term OPACs - the newly proposed acronym CIPACS (card-image public access catalogues) [3].

\section{Purpose and approach}

In this article, the main problems and issues concerned with the creation and implementation of CIPACs are identified and discussed. Mainly, two sources of information were used:

- a short "CIPAC Library Questionnaire" (CLQ) was sent out to 38 relevant libraries identified by mid-2001, in order to obtain details on their CIPACs;

- relevant project literature (reports, articles, papers, internal documents, information sheets).

Twenty-three libraries (of 38 that had been contacted) returned a questionnaire, and for 20 CIPACs some kind of project literature was retrieved. Because of the overlap between the two types of sources the following account is based upon 
Figure 2: The International CIPAC List: http:/ /novsrv3.ub.tuwien.ac.at/cipacs/c-i.html

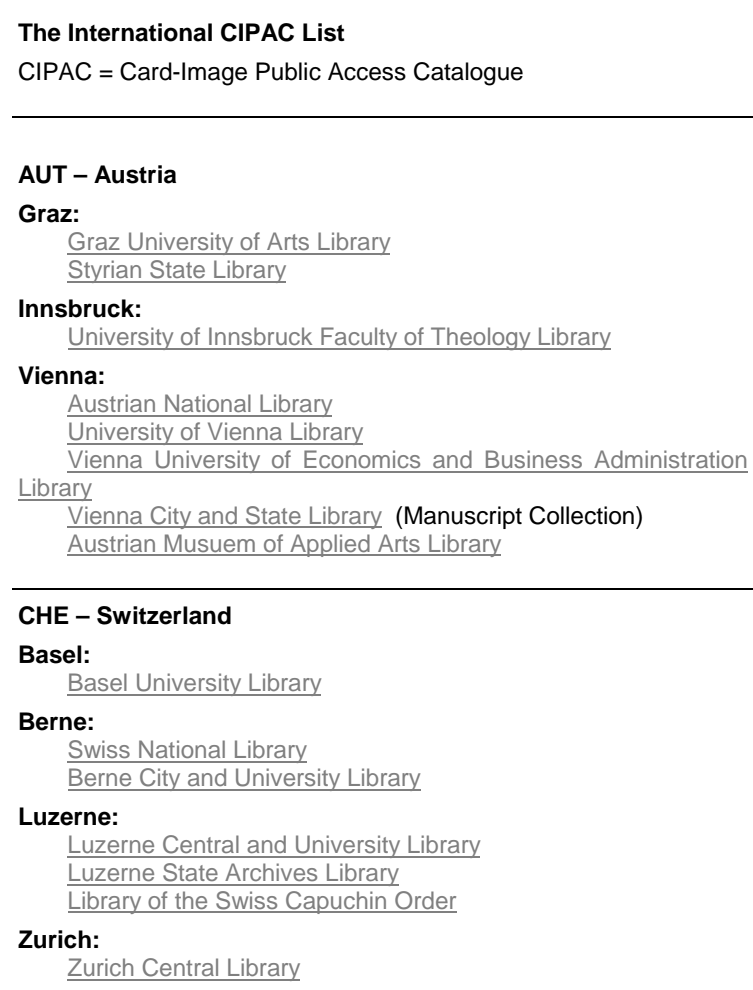

\section{CZE - Czech Republic}

Brno:

Moravian Library

\section{Prague:}

National Library of the Czech Republic

Parliamentary Library of the Czech Republic

Library of the Academy of Sciences of the Czech Republic

\section{DEU - Germany}

\section{Benediktbeuern:}

Philosophical-Theological College

\section{Berlin:}

Berlin Union Catalogue

Berlin Central and Regional Library

University Library, Freie Universität Berlin

Berlin Senate Library

Ibero-American Institute (Prussian Cultural Heritage Foundation)

Bochum:

Bochum University Library

Bonn:

Bonn University and State Library [test version]

Chemnitz:

Chemnitz University of Technology Library

Dortmund:

Dortmund City and Regional Library

Dresden:

Saxony State and Dresden University Library

Frankfurt:

HeBIS-Retro Union Catalogue

Göttingen:

Goettingen State and University Library (1946-1976)

Greifswald:

Greifswald University Library

Halle:

Saxony-Anhalt University and State Library

Hamburg:

Hamburg Institute of International Economics
Heidelberg:

Heidelberg University Library

Heidelberg University, Dept. of Psychology

Kiel:

Kiel University Library

Kiel Institute of World Economics Library

Leipzig:

Leipzig University Library

Magdeburg:

Magdeburg University Library

Munich:

Bavarian State Library

Munich Bundeswehr University Library

Münster:

Münster University Library

Potsdam:

$\underline{\text { Potsdam University Library - Babelsberg Library }}$

\section{ESP - Spain}

Barcelona:

Library of Catalonia

\section{FRA - France}

Paris:

Interuniversity Medical Library (Catalogue ancien 1477-1952)

GBR - United Kingdom

Edinburgh:

Edinburgh University Library (Special Collections)

London:

British Library of Political \& Economic Science (LSE) $\underline{\text { University of London Library }}$

\section{ITA - Italy}

Bologna:

Archiginnasio Library (Catalogo Frati-Sorbelli)

\section{Florence:}

Marucelliana Library

Central National Library [demo version]

Uffizi Gallery Library

Rome:

Alessandrina University Library

Trieste:

$\underline{\text { University Library }}$

LTU - Lithuania

Vilnius:

National Library of Lithuania

POL - Poland

Cracow:

Jagiellonian University Library

\section{USA - United States}

Princeton, NJ:

Princeton University Library

Richmond, VA:

Library of Virginia

(C) 2001-2002 by $\mathrm{O} \mathrm{C}$ Oberhauser (Vienna)

MSc dissertation on CIPACs (UCE Birmingham, 2002)

Last check/update: 30/11/2002 
Table 1: Comparison of CIPAC costs, per 100,000 cards (in Euros)

\begin{tabular}{|c|c|c|c|}
\hline Location & Institution & Cost $(€)$ Cost factors included & Source \\
\hline Vienna & National Library & 3,634.- scanning & Dikovich (2000) \\
\hline Vienna & Univ. Econ. Library & 7,267.- not specified & CLQ \\
\hline Zurich & Central Library & 25,613.- 'complete solution' (not specified) & ZB (1997) \\
\hline Brno & Moravian Library & 7,632.- scanning, hardware, software, external staff & CLQ \\
\hline Prague & National Library & 11,346.- scanning, implementation & CLQ \\
\hline Prague & Parliament Lib. & 13,609.- scanning, implementation(?) & CLQ \\
\hline Berlin & Central Library & $\begin{array}{l}\text { 11,504.- scanning, software, internet connectivity, security filming, } \\
\text { setting up server }\end{array}$ & $\begin{array}{l}\text { Rönsch (1998), } \\
\text { CLQ }\end{array}$ \\
\hline Frankfurt & $\begin{array}{l}\text { HeBIS-Retro Union } \\
\text { Catalogue }\end{array}$ & $\begin{array}{l}\text { 12,526.- scanning, OCR, categorisation, project management, } \\
\text { quality control, database loading, online ordering module }\end{array}$ & Dugall (2001) \\
\hline Halle & Univ. Library & $5,420 .-$ not specified & CLQ \\
\hline Hamburg & Maritime Agency & 11,003.- scanning, indexing, 'additional cost', software & CLQ \\
\hline Heidelberg & Univ. Library & 5,537.- scanning, indexing & $\begin{array}{l}\text { Dörpinghaus } \\
\text { (1998) }\end{array}$ \\
\hline London & $\begin{array}{l}\text { British Lib. of Pol. \& } \\
\text { Econ. Science }\end{array}$ & 11,136.- scanning, additional server capacity, in-house staff time & Price (2000) \\
\hline Bologna & Archiginnasio Lib. & 10,329.- scanning (front/back), indexing & Lunati (2001) \\
\hline Florence & Marucelliana Lib. & 10,866.- 'complete solution' (not specified) & Lunati (2001) \\
\hline
\end{tabular}

statements on 28 CIPACs. In addition, some information from CIPAC Web pages and from personal interviews with the creator of the Austrian National Library's CIPAC was used.

\section{Reasons for establishing CIPACs}

The four aspects listed in the CLQ, namely

- cost-effective / moderately priced method

- relatively fast way of converting a card catalogue

- savings in space (getting rid of card cabinets)

- universal access to the catalogue via Internet/WWW

were indeed the most important reasons why the respective libraries had chosen the CIPAC approach for the conversion of their card catalogues. It seems that cost, speed and universal access were about equally important (applying in most cases), whereas the space saving factor - although sometimes a crucial aspect - was, by and large, slightly less significant. Another motive that was mentioned repeatedly is catalogue preservation, especially when old catalogues existed only in one copy and the digitisation of the cards was also regarded as a measure for data security.

\section{Cost}

Undoubtedly, the creation of a CIPAC is less expensive than "real" retroconversion, but the difference in cost is not easy to determine. Practically all sources claimed that CIPACs are considerably cheaper; in some cases they were described as "the only affordable" or "the only financially feasible" way of converting the card catalogues into an online format. When comparisons with other conversion methods were made, the estimates varied between "half the price" (of using unskilled staff or students for conversion) and "ten percent" (of the cost for a professional retrospective conversion).

In addition, both the project literature and the CLQ provided a number of more concrete cost figures. However, these are rather difficult to compare because they vary with regard to (a) the cost factors covered (in-house costs are often not included), (b) kind of CIPAC (a binary search system does not need an index and is therefore cheaper), (c) currencies (some of which may have fluctuated over the years), and (d) time (scanning may have become cheaper over the past few years). Generally, they are not very precise either (e.g. in most cases it remains unclear if VAT - which also differs from country to country - is included or not). Nevertheless, in order to provide at least some kind of overview all these figures were converted to Euros [4] and standardised for a CIPAC size of 100,000 cards. The results of this attempt are given in Table 1 that also indicates which cost factors were covered by the respective figures.

In spite of all the shortcomings mentioned above, the table does indeed reflect the cost differences between the relatively cheap KatZoom 
Table 2: Cost factors for HeBIS-Retro, per 100,000 cards (in Euros)

\begin{tabular}{|c|c|c|}
\hline & Cost $(€)$ & \\
\hline \multirow{3}{*}{$\begin{array}{l}\text { External } \\
(89.8 \%)\end{array}$} & 11,248.- & \\
\hline & & 4,090.- scanning $(36.4 \%)$ \\
\hline & & $\begin{aligned} \text { 7,158.- } & \text { OCR processing, data } \\
& \text { transformation/categori- } \\
& \text { sation }(63.6 \%)\end{aligned}$ \\
\hline \multirow{5}{*}{$\begin{array}{l}\text { Internal } \\
(10.2 \%)\end{array}$} & 1,278.- & \\
\hline & & 447.- project management $(35 \%)$ \\
\hline & & 288.- quality control (22.5\%) \\
\hline & & 224.- database loading (17.5\%) \\
\hline & & $\begin{array}{l}\text { 319.- development of online } \\
\text { ordering module }(25 \%)\end{array}$ \\
\hline Total cost & $12,526 .-$ & \\
\hline
\end{tabular}

system (Vienna), the systems with indexes or virtual drawers (most others listed), and the rather expensive BerninaSpider system (Zurich). It leads to the assumption that the actual cost for an average partial index or virtual drawer system can be estimated at somewhere in the region of $€ 11,000$.- for 100,000 cards, or 11 Eurocents per card (VAT not included).

Even the costs for the more sophisticated HeBISRetro [5] system are about in the same region. The somewhat higher figure includes more cost factors, as shown in Table 2. It is interesting to note that the cost figure given for scanning ( $€ 0.041$ per card) is roughly comparable with the one shown for the Austrian National Library in Table 1 (€0.036), whereas a much higher amount (€0.099) was reported for the scanning of the British Library of Political \& Economic Science's card catalogue by a UK company.

\section{Speed}

Many CIPAC libraries had felt the need to have all their catalogue records available electronically as quickly as possible. Card-image online catalogues can indeed be created and made available over the World Wide Web in a very short time, i.e. between six months (Austrian National Library, 2.5 million cards) and one year (Princeton, 6 million cards).

Of all activities related to CIPAC creation, the scanning of the catalogue cards - even of large numbers - seems to be the speediest task. For example, the Theological Library at Innsbruck scanned its 190,000 cards within two weeks (CLQ); the Federal Maritime Agency at Hamburg needed only one week for 350,000 cards (CLQ). Quality control, creating the database, setting up the server, testing the CIPAC - all this takes much longer (e.g. in the latter case about half a year). Large institutions such as the Austrian National Library and the Berlin Central and Regional Library scanned their catalogues in daily batches of 40,000 to 60,000 cards (Dikovich \& Wilhelm 1997; Rönsch 1998). When done off-site, scanning requires more time, as in the case of the Bavarian State Library that shipped over two million cards in five batches from Munich to Berlin (Haller 1997), or the University of London Library that dispatched its 540,000 cards in batches of 50,000 for scanning (for which five months were planned; CLQ).

Pietzsch (2001a) points out that OCR processing is more time-consuming than one might expect. On average, per image (=catalogue card) seven seconds are required for reconstructing the text with OCR software on a Linux system. In the case of the Heidelberg University Library, more than three months (in day and night shifts) were needed for processing 1.2 million cards. At the $\mathrm{Zu}$ rich Central Library, 100,000 cards were scanned and OCR read per week (ZB 1997), which is about the same speed.

Complex solutions such as HeBIS-Retro take more time. The conversion of eight large catalogues (about 8 million cards) took about three years, plus an additional year for a public tender and various test installations (Dugall 2001). Nevertheless, this can still be considered as fast when compared with "normal" conversion. For example, Wicke (2000) reported that at the Dresden University Library six professional librarians (FTE) converted 266,000 records (350,000 volumes) in seven years, and Sosna (1997) estimated that his 1.5 FTEs at the Czech Parliamentary Library would need more than ten years for converting 200,000 volumes. According to Pietzsch (1998a), a full retrospective conversion of one million cards would have required between 50 and 100 person-years, whereas the conversion of the same catalogue into a CIPAC was achieved within a few months.

\section{Access}

Putting a card catalogue on the Internet or, correctly, the WWW, means to make it accessible 
universally, i.e. independent of location and time (e.g. a library's opening hours). However, not all institutions that created CIPACs did their original planning with the Web in mind. In about a quarter of the cases, solutions on in-house networks were first considered and/or implemented (one library even thought of microfiche first), but sooner or later replaced by Web-based CIPAC solutions. When it was first released to the public, the Princeton CIPAC was only to be used on a campus network and on dedicated workstations (Henthorne 1995). In 1993/94, this was probably the obvious thing to do; however, in the second half of the 1990s the reluctance of some libraries to opt for a Web-based solution straight from the beginning is more difficult to understand. Nevertheless, for the majority of libraries the Internet/ WWW was an absolute pre-requisite and the only option ever considered.

\section{Space}

In many cases the aspect of saving space by removing the old card catalogue(s) was an important reason for opting for a quick CIPAC solution. Most libraries suffer continuously from a shortage of space, and those that actually removed their card cabinets after their CIPACs had gone online gained at least one large room that could be used for other purposes (often for OPAC workstations). In some cases, the libraries moved to new or refurbished buildings and aimed at getting rid of their old cabinets on that occasion (e.g. Kiel, Dresden, London School of Economics).

What happened to the old card catalogues? In most cases they were removed from the reference section but kept in some other place. Only in a few instances the old catalogues were actually destroyed; e.g. at the Berlin Central and Regional Library the cards were pulped some time after the CIPAC had been introduced (Rönsch 1998; CLQ). At the Austrian National Library the removal of the public card catalogues caused some criticism by users and even in the press (CLQ).

\section{Preservation}

In many cases, and even when libraries wanted to get rid of the old catalogues, the creation of CIPACs was seen as a measure of catalogue preservation. For example, Stoklasová (1999: 8) men- tions that in the case of the Czech National Library's general catalogue the "cards themselves are historical artefacts and, as such, must be preserved". At the Austrian National Library, the only copy of the old subject catalogue had been exposed (unprotected) to the public for many years, so that the CIPAC was considered a security copy (Dikovich \& Wilhelm 1997). At Dresden the last security filming of the author/title catalogue had been made in 1942 so that a new one was urgently needed (Golsch \& Simmich 1999). Several other statements of this kind were found in the CLQs and the literature. Therefore, two (sometimes overlapping) aspects regarding security and preservation can be noted:

- the creation of a digital copy (CIPAC) makes it possible to remove an endangered old catalogue;

- the process of CIPAC creation leads to the availability of a security copy of the catalogue (either on CD-ROM or on roll film).

\section{Deciding about the kind of CIPAC}

When a library plans to create a card-image online catalogue, the question will arise what kind of CIPAC one intends to establish. What features will this catalogue have? What kind of browsing mechanism, what kind of image display? Will online ordering be made available? What software will be used, and should it be a commercial solution or a self-developed one? All these questions are not only interrelated but also depend on factors such as budget considerations, the kind of catalogue to be converted, and local aspects (e.g. the availability of a programmer in the library), to mention just the most significant ones.

When in 1992 the Princeton University Library was looking for a turnkey solution for its planned CIPAC, it was not so easy to find a suitable vendor (Henthorne 1995). Even today, the CIPAC software scene is rather scattered; there are far too many software solutions for a rather limited market, many of them home-made and/or installed only at one or two sites. Nevertheless, today libraries do have a choice when looking for CIPAC software, even if the number of commercially offered products is limited and in many cases the preference of certain features will still imply directly what software is to be used. 
Table 3: Reasons for the selection of CIPAC software

- good experiences of other libraries with this software this company

- system has good features/capabilities

- software developed by other library available at no low cost

- cost-effective system

6

5

5

- most cost-effective solution was to develop system 4 in-house

- Spider (OCR) not possible because many cards are hand- 2 written

- $\quad$ system is easy to use, user-friendly 2

- same system is used nation-wide 2

- turnkey solution, not much work by library staff required 2

- developing it together with software house was best solution 2

- software can be implemented quickly

Table 3 shows the reasons for the selection of the CIPAC software as mentioned in the CLQ and/or the literature:

This table leads to the suspicion that reasons such as low cost and availability at nominal cost [6] were sometimes more important than the actual features for searching and navigating. In other cases the librarians concerned were obviously impressed by a given CIPAC solution and decided to have something like this in their libraries, too. If in the process of software selection any detailed project planning was undertaken this was rarely disclosed. An exception is the SaxonyAnhalt University and State Library at Halle where the planners clearly had looked at some existing CIPACs and described exactly the software features desired (Lutze, Schnelling \& Worch 1999):

- navigation via an index covering every $50^{\text {th }}$ card

- browsing back/forth card by card

- temporary selection of a different step-width (e.g. 10 or 20)

- an appropriate module for adding, altering, deleting of images

- a feature for adding to the index

- a feature for the registration of all changes made

- an indication what catalogue is being searched

- the display of approx. four preceding and following index entries for navigation

- a feature for downloading images into a data file

- a printing option (to printer or to file)

- an online ordering feature (incl. printing out borrower slips)

\section{Technical aspects}

\section{Preparing the card catalogue}

With reference to the preparatory work done in the library, Rönsch (1998: 1566) in her account on the CIPACs at the Berlin Central and Regional Library succinctly states:

None. The reference catalogue was scanned as it was, straight from current use without any preparation, which means that sorting errors in the card catalogue are also reflected in the image catalogue. The division into three [catalogue sections] was kept. [7]

Presumably, a very similar approach was used in other libraries as well. Even if it would have been feasible to merge consecutive catalogue divisions, this was normally avoided; the same is true for systematic revisions of the filing sequence. However, there are also cases where considerable preparatory work was undertaken before the catalogues were scanned. The tasks that need consideration can be categorised as follows:

- Improving / completing the existing leader cards for use as a partial index, e.g. when unevenly distributed, as in the case of Princeton (Henthorne 1995) or when a subject CIPAC required a guide card structure of headings and subheadings, e.g. at Halle (Lutze, Schnelling \& Worch 1999);

- Creating indexes on the basis of drawer labels, leader cards, headings etc. (sometimes done by library staff; see also section on manual/intellectual input below);

- "Cleaning" of the drawers, e.g. removing glassine covers, re-typing cards that are badly damaged or illegible (Henthorne 1995);

- Removing duplicate cards (works that have already been catalogued for the OPAC); e.g. at Luzerne 45 person-months were needed for the removal of 450,000 cards (Niederer 1999); at Göttingen 810,000 of the 2.3 million cards were removed (Buschey, Halle \& Harms 2001);

- Checking the card catalogue for sorting errors (no evidence of realisation).

\section{Scanning and quality control}

Scanning can be performed either by the library itself (i.e. its staff and/or additional helpers, e.g. students) or by commercial firms (scanning bureaux, software vendors). In the first case it will normally be done in the library, but in the second case it can be done either on location or off-site (e.g. in the premises of a scanning bureau). 
When the Princeton University Library conducted its pioneering project, six million cards were scanned on the Library's premises by six purposely-hired students who worked with three scanners in two shifts (Henthorne 1995). The more recently created CIPACs were mostly scanned by commercial companies, especially in the case of the large libraries - in many instances as part of a package that also included database creation and software. Whether in-house or off-site scanning should be preferred depends on factors such as space (is there enough space in the library where scanning can be done without disturbing the users?), time (how much longer will it take when large quantities of cards must be shipped to the vendor's premises?), security (is it the only copy of a valuable catalogue which cannot be given away?), and vendors' preferences (e.g. concerning quality control) [8].

Scanning is normally done with high-speed scanners at a speed of up to 60,000 cards per day, at a resolution between 200 and 400 dots per inch, most often at $300 \mathrm{dpi}$. For most CIPACs only the front of every catalogue card was scanned, even if there was also information on the back [9]. The resulting digital images are usually bi-tonal, i.e. black and white (rarely grey-scaled or in colour), in TIFF format, often of the TIFF G4 (Group IV) standard [10]. According to Dikovich (1998), a 200dpi black and white card-image requires 6-7 kilobyte of storage space. The images are normally supplied on CD-ROM (occasionally also on magnetic disk, DVD, roll film).

According to all available sources, quality control is a time-consuming task but crucial for the functioning of the CIPAC, regardless what navigation/retrieval software will be used [11]. Today, quality control is usually part of the package offered by commercial vendors, but library staff is often involved, too. In particular, two aspects need to be checked - image quality and completeness (Schäuble 1996). Image quality refers to legibility, which must be equivalent to the original card. At 300 dpi this can be achieved without problems, but as a result of the not yet perfect automatic feeding of the scanners a certain proportion of the images will depict only parts of the cards or will be skewed. Completeness means both the correct sequence of the images and the existence of an image for every catalogue card (sometimes cards stick together so that no scan is taken of the second card). According to Köstler \& Schäuble (1998) the proportion of defective cardimages should be kept under 0.01 percent, especially if optical character recognition will be applied; Dugall (2001) mentions an error tolerance of less than 0.5 percent.

\section{Image standards and Web browsers}

As mentioned above, scanners normally produce digital images in TIFF format, the common standard for master images. However, the image formats suitable for Web browsers are GIF and JPEG, so that many digitisation projects create GIF or JPEG files from their TIFF masters for the subsequent delivery via the Web (Lee 2001: 45-46). In the case of CIPACs there are basically two approaches for the transmission of card-images on the WWW (Braune-Egloff 2000):

- Conversion of the TIFF images into GIF or JPEG format: This approach has been used in many CIPAC projects. However, card-images in the latter formats need more storage space than TIFFs which might be a problem, especially if cropped versions of these images need to be stored as well (for short displays of results);

- Alternatively, TIFF images can be transmitted and displayed in the browser by means of Java applets or plug-ins, i.e. software that downloads onto the browser and that supports not only the display of the TIFF image but also its manipulation (setting the image size, zooming in/out, changing the resolution, the brightness and the contrast, rotating the picture, inverting the colours, printing the card-image and downloading/saving it on the user's local workstation). This approach saves storage space and bandwidth, and also helps to avoid the problems of synchronising two image databases in case any changes are made. However, the applets and plug-ins require the use of a recent Web browser version and possibly a number of browser adjustments by the user (activation of Java and JavaScript support, accepting cookies, enabling of printing with Java applets, etc.). Some of these plug-ins may also come into conflict with other plug-ins installed on the PC or be incompatible with certain platforms (e.g. Macintosh computers).

\section{Optical character recognition}

Only a relatively small number of the present CIPACs are using BerninaSpider or similar software. For these libraries the use of OCR was beyond discussion because the software they had opted for was based on OCR-converted text. However, both from the CLQ and the literature it 
became evident that originally quite a number of other libraries had also experimented with OCR but soon given up because of poor results. They found that their catalogues contained a proportion of badly recognisable cards (hand-written, badly printed and partly damaged cards, cards with a variety of typefaces) that was too high for obtaining reasonable results via OCR. In several cases OCR was also described as too expensive some libraries just did not have the financial resources for this additional step, whereas others used "OCR" as a synonym for the Spider software which was considered as too costly.

In a study preceding the development of the Spider software, the developer group found out that for the catalogue of the Zurich Central Library the OCR process resulted in a word accuracy of 67 percent, which means that one in three words in the catalogue sample was incorrectly recognised (Mittendorf, Schäuble \& Sheridan 1995). The main difficulties for OCR were (a) the large variety of languages of the catalogue entries, with many accented characters, and (b) the large number of proper nouns and abbreviations; in both cases automatic dictionary lookup was not feasible. Pietzsch $(2001 a, 2001 b)$ mentions as the main problems for OCR (a) heterogeneous font face and font size, (b) amendments made on the cards (hand-written, different typeface), (c) varying degrees of blackness (from card to card, but also on the same card), (d) wear and tear (stains, dirt, mechanical damage), (e) variety of languages. Whereas Schäuble and Pietzsch made use of retrieval software with a high tolerance of errors, Dugall (2001: 118) highlights the importance of quality control and described various approaches for automatic quality checks and error correction used in the HeBIS-Retro project. He also emphasises that the OCR process is much more difficult than the preceding scanning step.

\section{Manual/intellectual input}

Both the KatZoom and the BerninaSpider CIPACs do not require manual or intellectual input for the creation of the respective CIPACs. When designing KatZoom, the Austrian National Library intended to keep things simple and decided to avoid the cost of index creation (Dikovich 2000), an aspect which was also attractive for the other libraries that subsequently used that software
(CLQ). The more sophisticated Spider system, by definition, does not require any manual work on the part of the library (except the preparation of the card catalogue for scanning).

The libraries using CIPACs with "virtual drawers" had to create indexes of the existing drawer headings and, in some cases, also of the headings of the original catalogue racks. This was obviously not a very costly and/or time-consuming task and therefore also attractive for the institutions concerned. For example, the University of London Library originally considered a more sophisticated index but found that its creation would take too long and cost too much, so that a simpler drawer label index of only 970 entries was established (CLQ).

For the CIPACs featuring partial indexes, longer and sometimes more sophisticated files had to be created. In the case of the Chopin systems, this task was often performed by the vendor, especially for the author/title catalogues where the headings of every $n^{\text {th }}$ card (e.g. every $20^{\text {th }}, 50^{\text {th }}, 200^{\text {th }}$ ) were used as entries; in other cases the libraries created the indexes themselves (e.g. Princeton). The latter was also true for subject CIPACs for which some libraries (a) keyed in classification schemes (Rönsch 1998), (b) created new subject indexes to the classification scheme (Lux 1997; Rönsch 1998), (c) checked and enriched the index entries produced by the vendor (Braune-Egloff 2000), or (d) created subject guide cards of headings and subheadings which the vendor could then use for index building (Lutze, Schnelling \& Worch 1999). The CIPAC of the Heidelberg University Library - featuring a full (not partial) index - is based on the headings of all 1.2 million catalogue cards which were keyed in by a commercial bureau; by means of appropriate software this index was then also permutated in order to facilitate easier browsing of the headings (Pietzsch 1998b). A rather lavish manual input project was undertaken for the Bavarian State Library's CIPAC [12].

\section{Servers, databases, system architecture}

In the case of most CIPACs implemented by commercial vendors (Chopin, BerninaSpider, and many individual solutions by various software houses) the server side of the system is just a "black box". Indeed, the libraries concerned need not worry 
about how their system is organised internally, all they usually need to do is provide/finance the hardware required for the server (usually a PC or workstation with sufficient memory and mass storage). The vendors themselves seem to prefer not to disclose the technological details of their systems. For example, the Chopin folder [13] informs just briefly on the components being used: Microsoft technology for Internet connectivity, ACCESS and SQL-Server for the databases, scripts in ASP and Java for retrieval, and Java applets for visualisation. To the author's knowledge, no information on the architecture of the Spider system is publicly available either. By contrast, the libraries that developed their CIPACs themselves had to deal with all technological details on the server side.

\section{Administrative tools}

In the CIPAC context an administrative tool is a software module that enables the library to make various kinds of changes in the card-image catalogue. Not all CIPACs are equipped with such a module; this applies not only to simple CIPAC applications but also to some of the more sophisticated CIPAC solutions. However, most CIPAC libraries that mentioned this issue in the CLQ and/or the literature seemed to be rather interested in such an administrative module. For example, the Halle project plan included three relevant requirements (Lutze, Schnelling \& Worch 1999):

- modifying, adding and deleting images at a later time must be supported by appropriate graphics tools;

- additions to the index must be possible (in case the Library wishes to index more images or even all images);

- all later modifications must be written to record files in order to make it possible that, in case the database needs to be rebuilt from the archive CDs, the most upto-date version can be restored again.

Of the wide range of possible applications of such an administrative module the following ones were mentioned most often:

- changing call numbers and/or locations, either by writing text onto the image (Chopin) or by replacing the card by a newly written one (KatZoom);

- putting "electronic stamps" on cards for which records have already been added to the "normal" OPAC; or (alternatively) deleting such cards from the CIPAC;
- replacing illegible or faulty cards by newly scanned or newly typed cards;

- changing the sorting position of images (in case of errors);

- correction of index entries (including characters not/wrongly recognised by OCR);

- making amendments to the index (e.g. by adding subject headings/subheadings).

\section{Organisational aspects}

CIPAC creation can be done completely in-house, or by out-sourcing various parts or even the whole of the project. There are cases were even the CIPAC system as such is operated by a vendor [14] or another institution [15].

The part most often done by a service agency is scanning (and OCR processing), even in those cases when the libraries did most of the projects themselves (e.g. at Heidelberg University). Also many other steps of CIPAC projects were performed by external firms. In some cases (e.g. Spider CIPACs, some Chopin CIPACs, Berlin Senate Library) the libraries preferred to hire a sole supplier in order to have the whole package - consulting services, project management, quality control, co-ordination, software and systems compatibility, and guarantee of conversion quality - supplied by the same company. It seems that unless such a full package was purchased, Perez' (1998: 64) recommendation to use an external library or information technology consultant for the validation of project planning and procedures, was hardly followed in any of the cases.

\section{CIPACs and the peculiarities of old catalogues}

\section{Physical form of old catalogues}

Not all former library catalogues were typed on $7.5 \times 12.5 \mathrm{~cm}$ or $3 \times 5$ inch cards. The older the catalogue the more likely it will be not only (partly) hand-written, but also

- on oddly shaped cards, slips or sheets (both in horizontal and vertical formats of different size);

- in the physical form of a sheaf catalogue (a batch of slips held together by some binding mechanism) [16] or a book catalogue (bound volumes with several or many catalogue entries per page). 
Figure 3: A hand-written card, partly in Old German script

\section{Steiermárkische Landesbibliothek Nominalkatalog bis 1945}

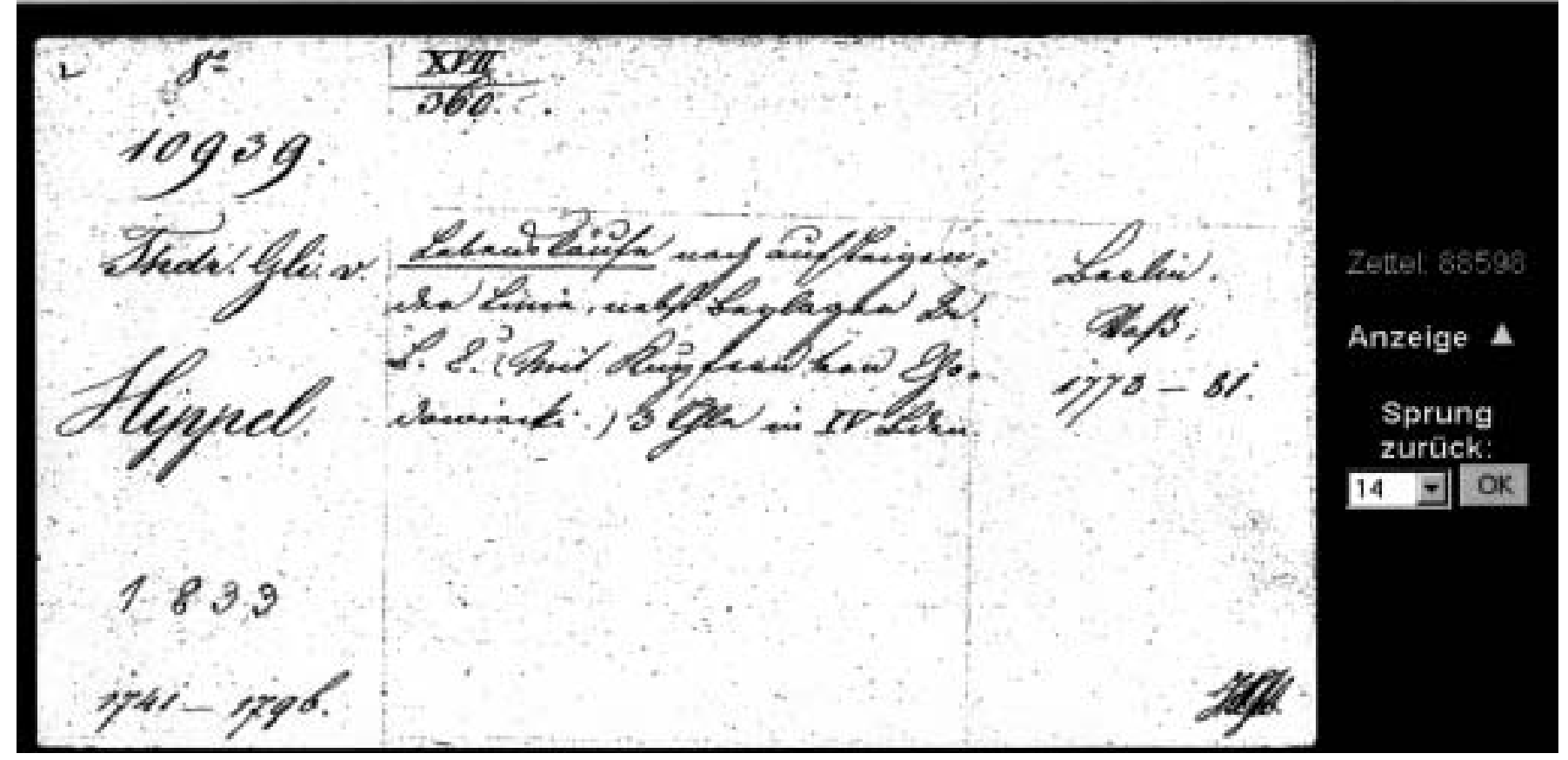

Some of these older catalogues cannot be scanned as easily and by high-speed batch scanning techniques as drawers of standard sized catalogue cards. Book catalogues can be processed with special book scanners; both a higher resolution (e.g. $400 \mathrm{dpi}$ ) and grey-scaling seem to be advisable (Angelus, Eichhorn-Berndt \& Schnelling 2000: 430). The University of Vienna Library's old book catalogue was not scanned from the original but from a microfiche version created in the 1980s (Dikovich 2000) [17].

Concerning navigation, it makes no difference whether a CIPAC is based on a sheaf catalogue or a card catalogue. In the case of book catalogues, things are more difficult, not only because the individual sheets are usually much larger but mainly because one sheet contains several or many catalogue entries. Only two solutions exist so far (a version of KatZoom that was adapted for the Viennese book catalogue, and a version of Chopin developed for classified book catalogues such as the ones at Halle and Leipzig).

\section{Old cataloguing rules}

Whereas in the case of "normal" OPACs the users need not be concerned too much about the under- lying principles and rules of cataloguing, the majority of CIPACs are as one-dimensional as the card catalogues on which they are based. This means that their users must have some basic understanding of the headings and the filing order used in the respective catalogues. Many CIPACs offer online help to explain such rules, sometimes at considerable length. However, most old catalogues are based upon rules for cataloguing and filing different from those used in the more recent past, so that the users of a CIPAC divided in chronological sections may easily be confused by a variety of such helpful recommendations. CIPACs in the German-speaking countries are affected worst because in many libraries the notorious "Prussian Instructions" (PI) were used - a set of rules developed in the $19^{\text {th }}$ century, based on grammatical rather than alphabetical principles and originally not made for end-users but for scholarly librarians. The users of the former card catalogues never managed to understand the PI, the present younger generation of librarians does not know them anymore and it can be assumed that hardly any CIPAC user will wish to deal with them. It is certainly a major criticism that some CIPACs are now carrying these idiosyncratic rules far into the online age. 
Simple CIPACs such as those of the KatZoom type are more affected by such old rules than others because their only access points are the letters of the alphabet - then it is up to the user to understand the filing sequence. In the case of systems that work with drawer labels or partial indexes some "repair work" can be done when the system is set up. An example is given by Fabian \& Haller (1998: 173-174) who describe the making of the drawer labels index for the CIPAC of the Bavarian State Library:

- as the letters "I" and "J" were inter-filed, drawer labels containing either were also keyed in with the other spelling, e.g. "JMM" (a cross reference for a journal title) was supplemented by "IMM" (in order to find "Imm, Emil");

- as many personal names were filed phonetically rather than alphabetically (e.g. Schmid, Schmied, Schmidt, Schmitt - all in one sequence), drawer labels containing such names were supplemented by additional index entries (e.g. "Schwarz, Ber..." by "Schwartz, Ber..."). [18]

\section{Legibility of old cards}

Legibility as a parameter of image quality has already been mentioned above. In this context, there is a second aspect of legibility that may affect some of the German and Austrian CIPACs, because in these countries on some of the handwritten catalogue cards the Kurrent script (Old German Script) [19] was used, which many of today's librarians and library users will not be able to read. An example of such a card is given in Figure 3.

\section{Presenting the CIPAC to the users}

\section{Naming the CIPAC}

When the Princeton University Library created the first major CIPAC, this previously unknown kind of reference tool was presented to the users as the "Electronic Card Catalog", but later on its name was changed to "Supplementary Catalog" in order to emphasise the fact that more and more cards were added to the OPAC and some of the information in the CIPAC might be outdated.

Unlike in the case of "normal" OPACs [20] no standardised terminology for CIPACs has been established yet. Therefore, it is not surprising that on library Web pages quite a variety of different
Table 4: Terms/phrases used for naming CIPACs on library Web pages

- digitised/ digital/scanned/ electronic/ online (version 16 of) card catalogue

- (card/author/subject/library/old) catalogue 15 until/ before 19xx

- image catalogue

- scanned/ digitised catalogue

- Webindex, online card index 5 2

terms is used for pointing/linking to CIPACs. These terms and phrases, as taken from the Web pages of all CIPAC libraries known so far, can be categorised as shown in Table 4. Only a few libraries created acronyms for their CIPACs, such as KatZoom (Vienna), DIKAT (Luzerne), DigiKat (Heidelberg), IPAC (Berlin), or CardPAC (Dortmund). As these acronyms are meaningless without an explanation, they are usually also accompanied by one of the terms or phrases listed in Table 4.

As shown in the table, often the term card cata$\log u e$ is used, together with some adjective that indicates that the digital form (and not the conventional one) is referred to [21]. Another frequently used type of expression refers to the period of chronological coverage rather than to the electronic form (e.g. Author catalogue until 1994). In a number of cases, the rather vague term image catalogue is used, particularly in German-speaking countries (spelled as "Image-Katalog" or "Imagekatalog"), whereas some other libraries named their CIPACs just scanned or digitised catalogues (without mention of the cards), which is not exact either.

Most libraries do not bother to provide further explanations of these names, some of which must be rather confusing for inexperienced library users. Only in a minority of cases, some sort of helpful mini-description is given, e.g.

- "an electronic copy of the former card catalogue, comprising digitised facsimiles of the catalogue cards" (University Library, Freie Universität Berlin);

- "just a copy (image) of the conventional original catalogue cards which were scanned" (Leipzig University Library) [22];

- "an online database of images that replicates catalog card indexes to selected library and archival collections"; “... contains a separate image for each catalog card" (Library of Virginia).

A few libraries also hint that their CIPACs are temporary catalogues for the time being, i.e. until 
all records will be added to the OPAC. Practically all of them fail to explain why this conversion method was chosen (e.g. cost, speed), thus leaving their users in the dark about why CIPACs exist alongside OPACs anyhow.

\section{Integration of CIPACs into OPACs and Web pages}

Most CIPACs are not integrated with the libraries' "normal" OPACs at all; normally, they only share with them a Web page with links to the various online catalogues (and sometimes databases) provided by the library. Most CIPACs do not even resemble their OPAC counterparts in terms of page design and layout.

One of the few exceptions is the Chopin CIPAC at Freie Universität Berlin that was designed to match the "corporate identity" of the University Library as also expressed in the other library Web pages, even if the CIPAC and the OPAC are not integrated yet (Braune-Egloff 2000). Other examples for integration include the Zurich Central Library (simultaneous searching of the CIPAC images and the OPAC of the Swiss Union Catalogue; CIPAC also linked with the Library's automated circulation system), and the Bavarian State Library (the CIPAC is a module of the general OPAC).

Also a few other libraries are planning some sort of integration, either with the OPAC's circulation module (e.g. Luzerne; Niederer 1999) or with its user interface (e.g. Freie Universität Berlin, Berlin Central and Regional Library), but by and large one cannot diagnose a trend into this direction.

\section{What do CIPAC libraries know about CIPAC users?}

Most libraries that returned the CLQ reported that their CIPACs were well received by the users, but practically all of these statements rely only on subjective impressions, on the reactions of individual users, some e-mail messages received from users, and other kinds of selective observation. Practically no attempts were made to record user reactions to CIPACs systematically (e.g. by conducting a user survey) [23].

Some libraries reported on various kinds of problems that individual CIPAC users had, e.g.
Figure 4: CIPAC use at the Austrian National Library in 2001

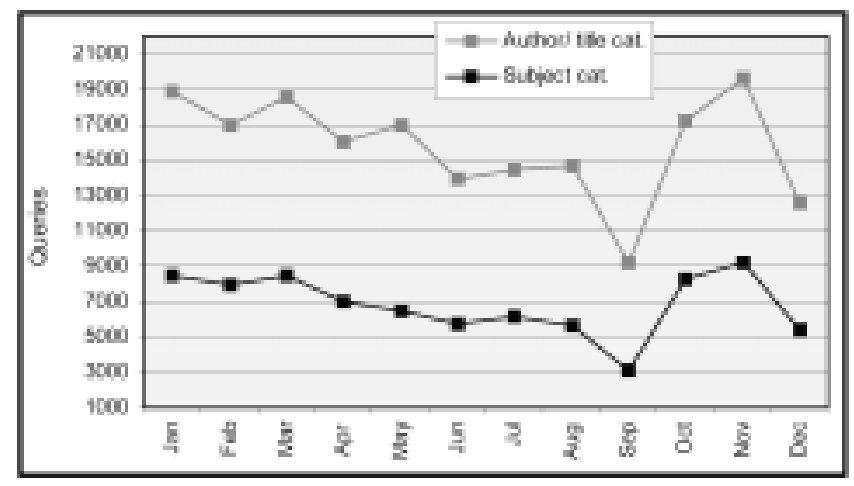

with (old) browsers, plug-ins for image display, slow system and/or network performance, legibility of cards, difficulties with navigation or even with working on a computer in general, whereas others mentioned that special instructional sessions were offered when their CIPACs were released. The Austrian National Library provided to the author a portfolio of collected complaint book entries, press cuttings (mostly readers' letters), email feedback etc. This collection indicates that some users were not happy with the KatZoom type of navigation (too cumbersome, no options for text searching) while others welcomed the accessibility of the old catalogues without the former restrictions of location and time. The majority, however, just lamented - often quite emotionally - about the removal of the card catalogues and made pleas for bringing them back to the Library's reference area.

Even if, generally speaking, CIPAC libraries do not know much about the users of their card-image catalogues, they seem to monitor whether their CIPACs are used at all, because in a number of cases figures were reported on the frequency of use (based on Web-server statistics and similar counting mechanisms). For example, often 1,000 users or more search the CIPAC of the Czech National Library per day (CLQ), and 500 the one of the Heidelberg University Library (Pietzsch 2001b); the statistical data that were used for the diagram in Figure 4 were provided by the Austrian National Library [24]. This diagram shows for both CIPACs (author/title catalogue, subject catalogue) a pattern that reflects the typical ups and downs in an academic year [25], but, more interestingly, it indicates that the subject catalogue is used quite consistently at about half the frequency of the author/title catalogue. 


\section{CIPACs: Interim or permanent solutions?}

Finally, the question arises what future CIPACs will have. Are they only a transient phenomenon or will they last for a longer period of time? In order to find out the view of the CIPAC libraries an appropriate question was asked in the CLQ. Also, the project literature was scanned for judgements concerning this issue; the results are shown in Figure 5.

The category a short-term solution applies to only two libraries that expect to complete the full conversion of their main catalogues as early as in 2003 (British Library of Political \& Economic Science, Austrian National Library). Of the others, the largest group considered their CIPACs as interim solutions for the time their other conversion activities (in many cases already ongoing) will take. However, some of these libraries mentioned that they were not sure how long this will take and if sufficient funds will be available, so that their CIPACs might become medium or long-term solutions. Most of those who chose the latter category had a similarly sceptical view, so that one could actually merge these two into one group of libraries that expect that their CIPACs will stay for a while. Some of the larger libraries with several catalogues in CIPAC format mentioned priorities concerning conversion speed so that some of their CIPACs would probably disappear sooner, others later and some maybe never. The relatively small group of libraries that considered their CIPACs as permanent were rather confident that this was the best or most realistic solution for their catalogues.

In reality, so far only one library has withdrawn card-image catalogues: The first two CIPACs of the Austrian National Library "lived" their short lives only from 1997 to 2000; then they were converted again and merged into one single OPAC. The next CIPAC to be closed might be the one at Princeton; the intention to do so (because of the completion of the Library's conversion project) was already announced in 2001 but has not been carried out so far.

\section{Concluding remarks}

It is interesting that CIPACs are basically a European phenomenon. Although the Princeton University Library was the first institution that ever
Figure 5: Estimation of the future of CIPACS

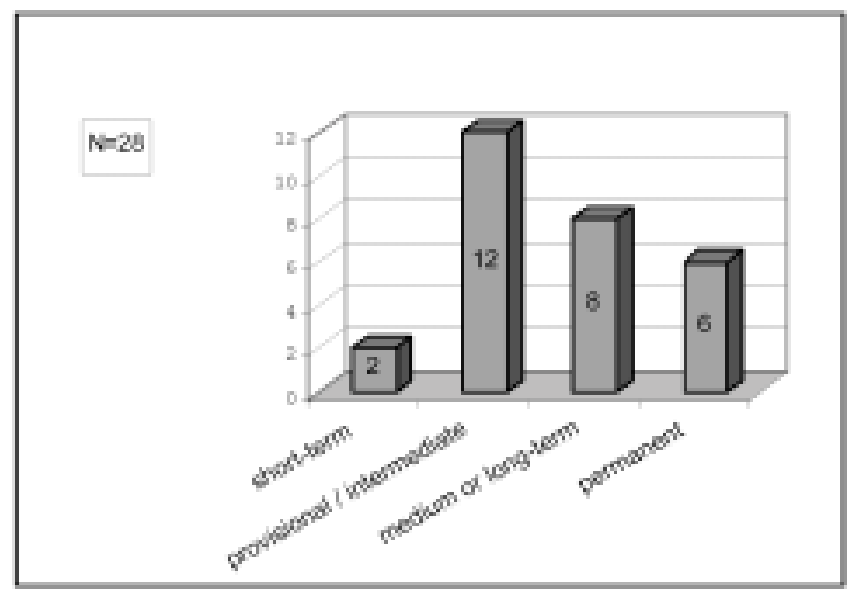

implemented a large card-image public OPAC and certainly did so with success -, there has been remarkably little resonance in the USA. To the author's knowledge, only one other US library [26] has employed the technique. The reasons for this might be that American libraries often enjoy better funding (making them more likely to afford a full catalogue conversion) and also the fact that the Old World holds a greater variety of ancient and/or hand-written card catalogues. It may well be that among the thousands of US libraries some more are using card-image OPACs; however, no mention of this has been found in the literature or on the WWW.

On the other hand, the Princeton project definitely influenced the development of CIPACs in Europe to a great extent. Here, the interest in card-image catalogues is still growing, more solutions of this kind are being implemented and new projects continue to be undertaken. As mentioned above, the number of CIPACs identified has already risen to sixty (December 2002), and more libraries in Austria, Germany and Italy are known to be considering or planning to establish such catalogues.

\section{Acknowledgement}

This article is a modified version of a chapter of his recently completed MSc dissertation; the gratitude of the author goes to Denis F. Reardon for his supervision and advice.

\section{Notes}

1. This component can be based on binary searching (i.e. browsing of iteratively reduced subsets of records, e.g. the Austrian KatZoom system), partial or full indexes (e.g. the German Chopin system), "vir- 
tual drawers" (i.e. indexes of the original drawer labels, e.g. the system developed at the British Library of Political \& Economic Science), or searching of OCR processed text (e.g. the Swiss BerninaSpider system). For a more detailed overview see Oberhauser (2003).

2. URL: http://www.ub.tuwien.ac.at/cipacs/c-i.html [viewed November 30, 2002]

3. This acronym was first proposed by Denis F. Reardon, University of Central England. Even if some of the image catalogues are electronic versions of sheaf and/or book catalogues, the majority are computerised card catalogues so that in this context, for convenience, "CIPAC(s)" will be used.

4. For this exercise, the conversion rates published on March 20, 2002, were used.

5. Conversion of eight large catalogues (approx. 8 million cards) with automatic recognition of the structural elements of the catalogue cards, plus development of a module for interlibrary loan (Dugall 2001).

6. For example, the Austrian National Library offered its KatZoom system to several Austrian institutions at a very reasonable price.

7. Originally in German (author's translation).

8. For example, of the eight catalogues that the Dresden University Library digitised, six were scanned in Berlin (the vendor's location) and two (the historical catalogues) on the Library's premises at Dresden (CLQ).

9. Although the Princeton catalogue had information on the back of 20 percent of the cards it was decided to scan only one side (Henthorne 1995). Only a few CIPACs feature double-sided card-images, e.g. those at Bologna and Florence.

10. An explanation of these technicalities can be found in Lee (2001: chapter 3)

11. At Princeton, 15 students and 40 library staff were needed for quality checks of every fifth image, and many cards had to be re-scanned (Henthorne 1995).

12. All drawer labels were keyed in by library staff; 21,000 guide card terms were merged into this index by the commercial firm that scanned the catalogue. The vendor was also commissioned to key in the text of all catalogue cards, partly categorised (author, title, year, and call number), partly as free text, with accuracy rates of 99.95 and 99.5 percent, respectively (Fabian 1997).

13. URL: http://62.104.137.109/chopin/info/prospekt _chopin.pdf [viewed August 20, 2002]

14. For example, the BerninaSpider CIPAC of the Luzerne Central and University Library is operated on a server of the EuroSpider company; the cost for this service is about $€ 10,250$.- per year (Niederer 1999).
15. E.g. the KatZoom CIPAC of the Austrian Museum of Applied Arts Library is hosted on a server of the Austrian National Library.

16. Pieces of wood connected by screws, belts made of woven material, etc.

17. This was possibly a cost-effective alternative but the image quality of this CIPAC must be described as not very good.

18. For this library's old catalogue the Old Munich Rules had been used (similar to the PI).

19. See also URL: http://www.germanscript.com/ history.htm [viewed April, 27, 2002]

20. These are normally presented on Web pages as the Online Catalogue or the OPAC (even in Germanspeaking countries, and often without explaining the acronym to the users), sometimes simply as the Library Catalogue or the Main Catalogue.

21. The term card catalogue without such a specification is often used for links to Web-pages that explain the libraries' (old) card catalogues, but normally not for CIPACs.

22. Both originally in German (author's translation).

23. As part of the author's MSc dissertation a Webbased exploratory survey of CIPAC users was undertaken (Oberhauser 2001; 2002).

24. For the purpose of this statistics, 10 calls of the underlying program scripts were defined as one CIPAC query (Dikovich 2002).

25. Including the Library's vacation period in September.

26. I.e. the Library of Virginia (Richmond, VA); see also Figure 2.

\section{References}

Angelus, A., C. Eichhorn-Berndt, and H. Schnelling. 2000. Digitalisierung des Realkataloges (HartwigKatalog) der Universitäts- und Landesbibliothek Sachsen-Anhalt und seine Visualisierung im Internet [Digitisation of the classified "Hartwig" catalogue of the Saxony-Anhalt University and State Library, and its visualisation on the Internet]. Bibliotheksdienst 34(3): 422-434.

Beyersdorff, G. 1993. Gesamtergebnisse und Empfehlungen [Total results and recommendations]. In: Weber, K., ed. Retrokonversion: Konversion von Zettelkatalogen in deutschen Hochschulbibliotheken: Methoden, Verfahren, Kosten. Berlin: Deutsches Bibliotheksinstitut: 285-311.

Braune-Egloff, D. 2000. Digitalisierung eines SchlagwortZettelkataloges [Digitisation of a subject card catalogue]. Freie Universität Berlin. URL: http://www. ub.fu-berlin.de/service/e_publikationen/mitarbeiter/ dbe/projektbericht.html [viewed: August 20, 2002].

Bryant, P. 1997. Making the Most of Our Libraries: Library Catalogue Access - the Issues and the Opportunities. Library Review 46(8): 554-560. 
Buschey, D., A. Halle, and R. Harms. 2001. Zwanzig Jahre Retrokonversion an der SUB Göttingen: Ein Zwischenbericht [Twenty years of retroconversion at the Göttingen State and University Library: An intermediate report]. Bibliotheksdienst 35(9): 10891102.

Dikovich, W. 1998. KatZoom: Technische Daten [KatZoom: Technical Data]. Vienna: Austrian National Library. [Internal document, 7p.]

Dikovich, W. 2000. Interview [conducted by the author at the Austrian National Library, Vienna, November 13, 2000].

Dikovich, W. 2002. Interview [conducted by the author at the Austrian National Library, Vienna, January 23, 2002].

Dikovich, W., and G. Wilhelm. 1997. KAT-ZOOM: Der neue Image-Katalog der ÖNB im Internet [KATZOOM: The new image catalogue of the Austrian National Library on the Internet]. Mitteilungen der Vereinigung Österreichischer Bibliothekarinnen und Bibliothekare 50(3/4): 50-57.

Dörpinghaus, H. .J. 1998. Kataloge der Universitätsbibliothek Heidelberg: Ein kurzer Streifzug durch die Geschichte [Catalogues of the Heidelberg University Library: A brief historical overview]. Theke: Informationsblatt der Mitarbeiterinnen und Mitarbeiter im Bibliothekssystem der Universität Heidelberg. Jahresheft: 9-14.

Dugall, B. 2001. Automatisierte Katalogkonversion einer Leihverkehrsregion [Automatic catalogue conversion within an interlibrary loans network]. $A B I-$ Technik 21(2): 112-124.

Fabian, C. 1997. Erfassen von Daten für einen ImageKatalog: Die Konversion des Alphabetischen Katalogs 1953-1981 (IFK) der Bayerischen Staatsbibliothek [Recording data for an image catalogue: The conversion of the alphabetical catalogue 1953-1981 of the Bavarian State Library]. Bibliotheksforum Bayern 25(3): 258-274.

Fabian, C., and K. Haller. 1998. Der Image-Katalog als alternatives Modell der Konversion: Die Konversion des Alphabetischen Katalogs 1953-1981 der Bayerischen Staatsbibliothek [The image catalogue as an alternative conversion model: The conversion of the alphabetical catalogue 1953-1981 of the Bavarian State Library]. Zeitschrift für Bibliothekswesen und Bibliographie 45(2): 167-188.

Golsch, M., and C. Simmich. 1999. Imagekataloge an der SLUB - Patentlösung oder Kompromiss? [Image catalogues at the Saxony State and Dresden University Library - patent remedy or compromise?]. SLUB-Kurier 13(4): 15-16.

Haller, K. 1997. Der Image-Katalog 1953-1981 der Bayerischen Staatsbibliothek [The image catalogue 1953-1981 of the Bavarian State Library]. Bibliotheksforum Bayern 25(3): 245-257.
Henthorne, E. 1995. Digitisation and the Creation of Virtual Libraries: The Princeton University Image Card Catalog: Reaping the Benefits of Imaging. Information Technology and Libraries 14(1): 38-40.

Köstler, H., and P. Schäuble. 1998. Vollautomatische Konversion von Zettelkatalogen: eine Weltneuheit in Bibliotheken [Automatic conversion of card catalogues: An innovation in libraries]. In: Böllmann, E., ed. Speicherbibliotheken - Digitale Bibliotheken: Wissen verteilen und bewahren. Frankfurt am Main: Klostermann: 86-89.

Lee, S. D. 2001. Digital Imaging: A Practical Handbook. London: Library Association Publishing.

Leeves, J., S. Butler, and A. Mealia. 1999. The CURL Database Project: Increasing Access to the Resources of Britain's Finest Research Libraries: Feasibility Study [...]. Stage One: Bibliographical Assessment and Methodology. Consortium of University Research Libraries. URL: http://www.curl.ac.uk/projects/dbproject.html [viewed: May 7, 2001].

Lunati, G. 2001. Cataloghi digitalizzati disponibili su Internet: Studio di confronto e valutazione [Digitised catalogues on the Internet: A comparative and evaluative study]. Rome: Ministero per i Beni e le Attività Culturali.

Lutze, G., H. Schnelling, and R. Worch. 1999. Zettels Traum: Digitalisierung von Zettelkatalogen in der ULB Sachsen-Anhalt und ihre Visualisierung im Internet [Digitisation of card catalogues at the SaxonyAnhalt University and State Library, and their visualisation on the Internet]. Bibliotheksdienst 33(5): 785-796.

Lux, C. 1997. Retrokonversion in der Senatsbibliothek Berlin [Retroconversion at the Berlin Senate Library]. In: Hoferer, K., ed. Retrokonversionsprojekte Planung und Durchführung: Referate und Materialien aus einer Fortbildungsveranstaltung des Deutschen Bibliotheksinstitutes. Berlin: Deutsches Bibliotheksinstitut: 15-30.

Mittendorf, E., P. Schäuble, and P. Sheridan. 1995. Applying Probabilistic Term Weighting to OCR Text in the Case of a Large Alphabetic Library Catalogue. In: Fox, E. A., et al., eds. Proceedings of the $18^{\text {th }}$ Annual International ACM SIGIR Conference on Research and Development in Information Retrieval: SIGIR '95, July 9-13, Seattle, WA. New York, NY: ACM Press: 328335.

Müller, C. 2002. The Austrian National Library's card image catalog. OCLC Systems \& Services 18(3): 146152.

Niederer, U. 1999. DIKAT: Der Zettelkatalog der ZHB Luzern im Internet [DIKAT: The card catalogue of the Luzerne Central and University Library on the Internet]. ARBIDO (10). URL: http://www. eurospider.ch/eurospider/products/bernina_arbido _prod.html [viewed June, 30, 2000]. 
Oberhauser, O. 2001. Web-Umfrage zur Benutzung von Card-Image Online-Katalogen, Teil 1: Anlage und Durchführung der Befragung [Web survey on the use of card-image online catalogues, part 1: Conception and carrying out of the survey]. Bibliotheksdienst 35(9): 1014-1026. URL: http://bibliotheksdienst. zlb.de/2001/01_09_02.pdf [viewed July 12, 2002].

Oberhauser, O. 2002. Web-Umfrage zur Benutzung von Card-Image Online-Katalogen, Teil 2: Ergebnisse der Befragung [Web survey on the use of cardimage online catalogues, part 2: Results of the survey]. Bibliotheksdienst 36(8/9): 1065-1090.

Oberhauser, O. C. 2003. Card-image public access catalogues (CIPACs): An international survey. Program: Electronic library and information systems 37(2) [forthcoming].

Perez, E. 1998. Converting a Card Index Backfile. Database 21(6): 63-65.

Pietzsch, E. 1998a. Die Digitalisierung des Alphabetischen Zettelkataloges 1936-1985 [The digitisation of the alphabetical card catalogue 1936-1985]. Theke: Informationsblatt der Mitarbeiterinnen und Mitarbeiter im Bibliothekssystem der Universität Heidelberg. Jahresheft: $15-17$.

Pietzsch, E. 1998b. Kostengünstige Digitalisierung eines Zettelkataloges [Economical digitisation of a card catalogue]. Zeitschrift für Bibliothekswesen und Bibliographie 45(5): 479-494.

Pietzsch, E. 2001a. Die Stichwortsuche im DigiKat [Keyword searching of the DigiKat]. Theke: Informationsblatt der Mitarbeiterinnen und Mitarbeiter im Bibliothekssystem der Universität Heidelberg. Jahresheft: 21-24.

Pietzsch, E. 2001b. Volltextindizierung von Zettelkatalogen: Wie kann in Millionen sehr kurzer OCR-Texte schnell und fehlertolerant gesucht werden? [Index- ing a large library catalogue: How to search short OCR texts rapidly and with a high tolerance for errors]. ABI-Technik 21(3): 206-218. URL [preprint]: http://www.ub.uni-heidelberg.de/archiv/1787 [viewed July 12, 2002].

Price, G. 2000. Card catalogue retro-conversion and digitisation: Strategy adopted by British Library of Political \& Economic Science (LSE). London: BLPES. [Internal document, 2p.]

Rönsch, H. 1998. Image-Katalog im Internet: Komfortable Recherche - preisgünstige Methode [Image catalogue on the Internet: Convenient searching economical approach]. Bibliotheksdienst 32(9): 15651573.

Schäuble, P. 1996. Kostengünstige Konversion grosser Bibliothekskataloge [Economical conversion of large library catalogues]. ABI-Technik 16(2): 165-166.

Sosna, K. 1997. New Developments in Library Services and Technology: Modernization of Information Services of the Parliamentary Library of the Czech Republic. $63^{\text {rd }}$ IFLA Council and General Conference, Copenhagen, Denmark, 1997. URL: http://www.ifla.org/IV/ ifla63/63sosk.htm [viewed February 2, 2001].

Stoklasová, B. 1999. Retrospective Conversion in Czech Libraries. LIBER Annual General Conference, Prague, 6-10 July, 1999: Changing Missions, Changing Skills.

Wicke, L. 2000. Konversionsprojekte: Von konventionellen $\mathrm{zu}$ elektronischen Katalogen [Conversion projects: From conventional to electronic catalogues]. SLUB-Kurier. 14(3): 8-9.

ZB. 1997. ZB revolutioniert Informationssuche: Der 100 Jahre alte Zentralkatalog auf Internet abrufbar [Zurich Central Library revolutionises information retrieval: The 100 year old central catalogue on the Internet]. Neue Zürcher Zeitung 31, February 7: 5.

\section{Editorial history:}

paper received 28 August 2002;

final version received 13 December 2002;

accepted 13 December 2002. 